\title{
Prognostic Significance of Concurrent MYC, BCL2 and/or BCL6 Expression in Diffuse Large B-Cell Lymphoma
}

\author{
MOHEBAT H. GOUDA, M.D.*; MOSTAFA M. AMER, M.D.** and MOHAMMED ABD ELMONEM, M.D.*** \\ The Departments of Pathology, Faculty of Medicine-Benha University*, Clinical Pathology, Faculty of Medicine, \\ Al-Azher University, Assuit** and General Surgery, Faculty of Medicine, Benha University***
}

\begin{abstract}
Background: DLCL with aberrations in MYC, BCL2 and/or BCL6 due to genetic alterations or protein expression is a high grade $\mathrm{B}$-cell lymphomas with poor prognosis if received standard RCHOP chemotherapy. So that, different regimens are needed for better prognosis.

Aim of the Study: Identify the association of protein, genetic expression of MYC, BCL2, and/or BCL-6 in cases of DLBCL, if MYC IHC could be used as a screening test to determine DHL or THL status, and to determine if the DHL or THL biology are related to any clinic-pathological features.

Material and Methods: Thirty patients who were diagnosed with primary DLBCL from July 2015 to July 2018. The cases were collected from General surgery department-Faculty of medicine- Benha University and Assiut faculty of medicineAl-Azhar University were identified after applying exclusion and inclusion criteria. Clinico-pathological data was obtained by review of medical records and biopsy specimens for IHC and FISH were obtained from the Departments of general surgery. The FISH test (for MYC, BCL2, and BCL-6) and IHC (for CD10, KI 67, MYC, BCL2, and BCL-6) were performed. Statistical analysis was performed using IBM SPSS Statistics for Windows, version 16 ( $p$-value $<0.05$ was considered significant and $<0.01$ was highly significant). This study was approved by the Research Ethics Committee MoHP, under protocol no. 595 of 2012).
\end{abstract}

Results: Double hit gene rearrangements by FISH were detected in $3 / 30(10 \%)$ patients. MYC IHC was positive in $6 / 30(20 \%)$ cases, and 3 of these 6 cases $(50 \%)$ were FISH positive. Sensitivity, specificity and concordance of MYC IHC as a screening tool were $100 \%, 73.6 \%$ and $50 \%$, respectively. BCL2 staining was positive in $14 / 30(46.6 \%)$ cases, and only 3 of the 14 cases $(21.4 \%$ ) were FISH positive. $6 / 30$ $(20 \%)$ cases were positive for both MYC and BCL2 by IHC (double protein expresser status) and 3 of these $6(50 \%)$ cases were positive by FISH. DHL biology showed an association with many clinico-pathological parameters including elevated serum Lactate dehydrogenase, stage III,IV, Bone marrow infiltration, extranodal involvement, and overall survival.

Conclusion: The association between MYC IHC and FISH in the current study was statistically significant. The

Correspondence to: Dr. Mohebat H. Gouda,

The Department of Pathology, Faculty of Medicine-Benha University sensitivity of MYC in our study was $100 \%$, we can propose that it can be used as an effective screening test if similar results can be validated in larger studies. The current study supports the practice of routinely testing for MYC and BCL2 status in all cases of DLBCL, irrespective of clinical features of the disease, to identify the high-risk DHL subset of patients, who can be candidates for more intense newer chemotherapy regimens and for prognostic purposes.

Key Words: Lymphoma - Diffuse large cell lymphoma (DLCL) - Cytogenetics - Fluorescence in situ hybridisation (FISH) - Immunohistochemistry - Doublehit lymphomas (DHL).

\section{Introduction}

DLBCL is the commonest type of non-Hodgkin lymphoma (NHL), representing about $30-40 \%$ of NHL cases. It is a different group of diseases [1] Some cases of high grade lymphoma arise on top low grade lymphoma as follicular lymphoma due to the occurrence of additional events [2] .

BCL2, BCL6, and MYC genes are frequently undergo mutation in DLBCL. The 2016 revision of the World Health Organization (WHO) that classify lymphoma included a different subtype of lymphoma, differs from DLCL, known as highgrade B-cell lymphoma with translocations involving myc and bcl- 2 or bcl- 6 as identified by fluorescence in situ hybridization (FISH) or standard cytogenetics [3], termed as double-hit lymphomas (or triple-hit lymphomas if all 3 rearrangements are present). The "first-hit" is a MYC rearrangement [4] . Derangements of both BCL2 and BCL6 may be the "second hit" or "third hit." [5].

Using the immunohistochemistry to detect the expression of MYC protein resulted in the identification of some lymphomas associated with protein overexpression of MYC and BCL2 genes in absence of genetic rearrangements [6]. Dual-expresser protein, or double protein, refers to immunohisto- 
chemical detection of MYC and BCL2 overexpression. This profile was referred to as the "doubleexpressor" phenotype in DLBCL in the revised World Health Organization (WHO) classification of lymphoid neoplasms, which was published in 2016 in Blood [7].

We must differentiate between double-hit lymphomas (or triple-hit lymphomas) and the larger group of double-expressor lymphomas, that showed IHC over-expression of MYC and BCL-2 and/or BCL-6, through using variable cutoff values to define positivity [8]. Cases with double-hit lymphomas have worse outcome if treated with standard chemotherapeutic regimen with high incidence of CNS metastasis. DHL may arise as a result of the transformation of the underlying indolent lymphoma [9].

C-Myc is an important "global" transcription factor that has roles in cell proliferation and growth. It is located on chromosome 8q24. in normal states, it is strictly regulated, resulting in low cMYC protein levels, that able to activate apoptosis under normal physiological conditions [10]. The cmyc geneusually known as a bona fide oncogene, that can cause cell transformation through uncontrolled over-expression of intact c-MYC protein [11]. The c-myc gene translocation with an immunoglobulin gene is the genetic hallmark of Burkitt lymphoma (BL) and is essential for that diagnosis. MYC over-expression leads to continuous cell growth, division, and metastasis [12] .

BCL2 gene antagonizes apoptosis, and its dysregulation leads to prolonged cell survival. in normal states, BCL6 encodes a transcription repressor, its over-expression causes suppression of several genes as P53 tumor suppressor gene that prevent apoptosis of cells with damaged DNA [13] Theoretically, lymphomas with mutations that cause continuous cell growth and prevent apoptosis leading to prolonged survival of malignant cells. inactivation of MYC gene is caused by the action of BCL6, the main regulator of the germinal centre $[14,15]$.

BCL-2 translocation, commonly present in cases with follicular lymphoma, it is present in $45 \%$ of cases of DLBCL and is a marker of worse outcome. Recently, there are many studies for targeted therapies for this marker, promising the development of drugs that antagonize the functions of BCL2 [16].

BCL6 (3q) encodes the BCL6 protein which has a great role in the differentiation of normal germinal centre B lymphocytes. BCL-6 controls a transcriptional programme which facilitates the entry of precursor B cells into the germinal centre of the follicle [17]. It modulates and inhibits the reactions of the germinative centre, leading to its formation and maintenance. If this gene is desregulated, that will lead to lymphomagenesis and is detected in $30 \%$ of DLBCL patients [18]

\section{Aim of the work:}

Our primary objective was to detect the relation between protein and genetic expression of MYC, BCL2, and/or BCL-6 in cases of DLBCL through comparing the results of IHC and FISH. The secondary objectives were to determine if MYC IHC could be used as a screening test to determine DHL or THL status, to determine if the double hit or triple hit biology are associated with any clinicpathological features.

\section{Patients and Methods}

This study was done on selected 30 cases of patients diagnosed as DLBCL from General surgery department-faculty of medicine-Benha University and general surgery department of Asiut faculty of medicine, Al-Azhar University. Records were reviewed from July 2015 to July 2018. After institutional approval of the study protocol and obtaining fully informed written patients consent for participation in the study. Patients were evaluated in surgical OPD for lymphadenopathy by detailed history taking, general and local examination. Clinical informations were reviewed, including history of non-Hodgkin lymphoma (NHL), nodal and/or extranodal involvement, central nervous system (CNS) involvement, bone marrow infiltration, levels of lactic dehydrogenase (LDH), staging, and recurrences.

\section{Inclusion criteria for this study were:}

1- Significant lymphadenopathy for more than 2 weeks without presence of infectious cause, with no response to conservative treatment and/or clinical suspicion of malignancy.

2- Post operative (lymph node biopsy) pathological diagnosis of DLCL.

\section{Exclusion criteria for this study were:}

1- Lymph node biopsy was done as a part of more elaborate procedure, for example: Neck dissection for a known head and neck cancer with cervical lymphadenopathy.

2- Post operative (lymph node biopsy) pathological diagnosis was not DLCL (other type of lymphoma or any other pathological diagnosis). 


\section{Morphological features:}

Hematoxylin and eosin (HE) slides of the 30 selected biopsies were evaluated according to the morphological criteria defined by the revised World Health Organization (WHO) classification of lymphoid neoplasms, which was published in 2016 [7]. The parameters adopted in this study were monomorphic/polymorphic cytological pattern, diffuse growth, cytoplasmic eosinophilia, necrosis, mitotic activity, apoptosis, stromal sclerosis.

\section{Immunophenotypic evaluation:}

The corresponding cell blocks were cut $4 \mu \mathrm{m}$ thick, mounted on positively-charged slides. The steps of staining followed the standard ABC (avidin-biotin complex) procedure using the Ultra Vision Detection System (Anti-polyvalent, HRP/ $\mathrm{DAB}$, ready-to-use, Lab Vision corporation). Antigen retrieval was done with microwave treatment in $10 \mathrm{mM}$ citrate buffer (Neo-Markers, Cat.\# AP9003), pH 6.0. The markers used were: CD10 (clone 56C6, ready to use, Dako), Bcl6 (PGB6-P clone, ready to use, Dako), Bcl2 (clone 124, ready to use, Dako), Myc (clone EP121, ready to use, Biocare) and Ki67 (Clone MIB-1, ready to use; Dako). Appropriate positive and negative controls were included. The freshly prepared DABsubstrate-chromogen solution was applied.

According to Olivera, et al., [14] the expression of CD 10 was evaluated if being positive or negative. The markers Myc, Bcl2 and Bcl6 were evaluated through calculating percentage of cellular expression. For Myc and BCL6, cases were defined positive if the nuclear expression was $>50 \%$ of tumor cells. For $\mathrm{Bcl} 2$, the cases were recorded positive if $>70 \%$ of cells stained by the marker. Cases stained by Ki67 for detection degree of was classified into $<90 \%$, and $>$ $90 \%$.

\section{Fluorescence in situ hybridization (FISH):}

According to Kasireddy, et al., [19] Fluorescence in situ hybridization (FISH) analysis was performed for formalin-fixed, paraffin-embedded tissue samples; FISH was done according to the manufacturer's protocol. The signals from 200 nuclei were examined to detect loci of the MYC (Vysis LSI MYC-IGH dual color, orange and green, break apart rearrangement probe; Abbott Molecular Des Plaines, IL, USA), BCL2 (Dako, BCL2 FISH DNA, red and green, probe split signal) and BCL6 genes (Vysis LSI, BCL6, dual color, orange and green, break apart probe rearrangement; Abbott Molecular Des Plaines, IL, USA), following the manufacturer's instructions. The FISH results were examined by fluorescence microscopy (BX61; Olympus, Center
Valley, PA) with suitable filters and the images were taken with a Q-Color 5 Olympus digital camera. A case was positive if $5.0 \%$ of the cells (at least 40 tumor cells were counted) of a sample showed separate orange/red and green signals.

\section{Statistical analysis:}

Statistical analysis was performed using the SPSS version 16.0 (Chicago, SPSS Inc. USA) for windows software package according to Sperman's correlation coefficient. Correlation between several variables was computed using Fisher's exact test. $p$-value $<0.05$ was recorded significant and $<0.01$ was considered highly significant. Overall survival (OS) was calculated from the date of diagnosis to the date of death or last follow-up.

\section{Results}

The 30 patients were submitted for clinical review, morphological analysis, immunohistochemistry and molecular evaluation. FISH analysis detected three cases of DHL. The two groups defined by the cytogenetics investigation were, DHL $(n=3)$ and DLBCL $(n=27)$; the clinical, morphological, immunohistochemical and cytogenetic data are shown in Tables $(1,2,3)$ respectively.

\section{The clinical features of examined cases:}

Among patients with DLBCL, males represented $(55.5 \%)$ with a mean age of 61 years (range: $25-69$ years), $59.3 \%$ of patients were $>61$ years. Regarding the clinical features, two patients were initially presented with extranodal mass. bone marrow infiltration in $14.7 \%(4 / 27)$ and in the CNS in 2 patients (7.4\%). 12 cases $(44.4 \%)$ presented at stage III or IV. As for clinical outcomes in the DLBCL group, 13 of the 27 cases (48.1\%) resulted in death about 12 months after diagnosis.

The 3 patients of DHL (Table 1) were men, over 61 years old, previously diagnosed as DLBCL. Two patients were initially presented with extranodal mass. Bone marrow infilteration in 2 cases but no CNS infiltration in all the three patients. 2 of these cases presented at stage III or IV. The clinical course of the DHL patients was death in three, four and five months.

\section{Histopathological features:}

Among the 30 cases of DLBCL, the main growth pattern was the diffuse pattern $(100 \%)$ and $70.4 \%$ of cases showed mitosis. In the DHL group, the typical morphology in our study was diffuse monomorphic pattern, eosinophilic cytoplasm and apoptotic elements. The sclerosis or nuclear lobulation were not observed in this group (Table 1). 
Immunohistochemical Results:

In the DLBCL group, 12 cases $(44.4 \%)$ were CD10 positive, 9 cases $(33.3 \%)$ were BCL6 positive, 11 case $(40.7 \%)$ were $\mathrm{Bcl} 2$ positive and 3 patients (10\%) were positive for Myc. Cell proliferation, measured by Ki-67, was higher than $90 \%$ in three $(11.1 \%)$.

The three DHL had a B immunophenotype. 3 cases were positive for both MYC and BCL2. BCL6 were negative in all three biopsies. Cell proliferation, measured by Ki-67, was higher than $90 \%$ in two cases $(66.7 \%$ ) ( Table 2- Fig. 1, $\mathrm{B}, \mathrm{C}, \mathrm{D}, \mathrm{E}, \mathrm{F})$.

\section{Molecular results:}

Molecular cytogenetic by FISH showed that in the DLBCL group, positivity for MYC, BCL2 and BCL6 was determined in one (3.7\%), 2 (7.4\%) and 2 cases $(7.4 \%)$, respectively. The three DHL patients presented translocation of the MYC gene simultaneously with the BCL2gene translocation. There were no cases of triple-hit lymphoma (Table 3- Fig. 1,G,H,I).

\section{From Table (3), it is concluded that:}

- Statistically high significant positive correlation between the immunohistochemical expression of c-myc,and bone marrow/CNS infilteration,recurrence, and death ( $p$-value $p<0.01$ ).

- Statistically high significant positive correlation between the immunohistochemical expression of BCL-2 and LDH level, bone marrow infilteration, and death $(p$-value $p<0.01)$.

- Statistically high significant positive correlation between the immunohistochemical expression of BCL- 6 , and bone marrow infilteration, and death ( $p$-value $p<0.01)$.

- Statistically high significant positive correlation between the immunohistochemical expression of c-myc, and IHC expression of BCL-2 and BCL-6 ( $p$-value $p<0.01)$.

Positive Myc detected by IHC was reported in 6patients, $3(50 \%)$ of them showed also positivity in the FISH test ( $p=0.0667)$. For this marker, the IHC technique had high specificity $(85 \%)$ with low sensitivity (38\%). Regarding $\mathrm{Bcl} 2,14$ cases showed positive IHC expression, from which 3 cases $(21.4 \%)$ showed concomitant positive cytogenatic analysis. None of the 9 patients that showed positivity for Bcl6 by IHC showed positive FISH $(p=0.375)$, denoting poor agreement between the two methods for this marker. The findings related to BCL6 gene showed no statistical significance.

Table (1): Clinicopathological data of the diagnosed groups after FISH.

\begin{tabular}{|c|c|c|c|c|c|}
\hline & \multicolumn{4}{|c|}{ Diagnostic Groups after FISH } & \multirow{3}{*}{$\begin{array}{c}p- \\
\text { value }\end{array}$} \\
\hline & \multicolumn{2}{|c|}{ DLBCL $(n=27)$} & \multicolumn{2}{|c|}{ DHL $(n=3)$} & \\
\hline & No. & $\%$ & No. & $\%$ & \\
\hline $\begin{array}{l}\text { Mean age: } \\
\quad \leq 61 \\
\quad>61\end{array}$ & $\begin{array}{l}11 \\
16\end{array}$ & $\begin{array}{l}40.7 \\
59.3\end{array}$ & $\begin{array}{l}0 \\
3\end{array}$ & $\begin{array}{l}0 \\
100\end{array}$ & $p<0.05$ \\
\hline $\begin{array}{l}\text { Sex: } \\
\quad \text { Male } \\
\text { Female }\end{array}$ & $\begin{array}{l}15 \\
12\end{array}$ & $\begin{array}{l}55.5 \\
44.5\end{array}$ & $\begin{array}{l}3 \\
0\end{array}$ & $\begin{array}{l}100 \\
0\end{array}$ & $p<0.05$ \\
\hline $\begin{array}{l}\text { Monomorphism } \\
\text { Polymorphism }\end{array}$ & $\begin{array}{l}20 \\
7\end{array}$ & $\begin{array}{l}74.1 \\
25.9\end{array}$ & $\begin{array}{l}3 \\
0\end{array}$ & $\begin{array}{l}100 \\
0\end{array}$ & $p>0.05$ \\
\hline $\begin{array}{l}\text { Diffuse growth } \\
\text { Follicular pattern }\end{array}$ & $\begin{array}{l}27 \\
0\end{array}$ & $\begin{array}{l}100 \\
0\end{array}$ & $\begin{array}{l}3 \\
0\end{array}$ & $\begin{array}{l}100 \\
0\end{array}$ & $p>0.05$ \\
\hline Mitosis & 19 & 70.4 & 1 & 33.3 & $p<0.05$ \\
\hline Necrosis & 10 & 37.1 & 3 & 100 & $p<0.05$ \\
\hline Cytoplasmic esinophilia & 9 & 27 & 3 & 100 & $p<0.05$ \\
\hline Stromal sclerosis & 7 & 25.9 & 0 & 0 & $p<0.05$ \\
\hline
\end{tabular}

Table (2): Immunohistochemical data of the diagnosed groups after FISH.

\begin{tabular}{lccccc}
\hline & \multicolumn{3}{c}{ Diagnostic Groups after FISH } & \\
\cline { 2 - 4 } IHC markers & DLBCL $(\mathrm{n}=27)$ & \multicolumn{2}{c}{ DHL $(\mathrm{n}=3)$} & \\
& No. & $\%$ & No. & $\%$ & \\
\cline { 2 - 4 } & 12 & 44.4 & 0 & 0 & \\
\hline vD10 & 11 & 40.7 & 3 & 100 & \\
BCL-2 & 9 & 33.3 & 0 & 0 & $p<0.05$ \\
BCL-6 & 3 & 11.1 & 3 & 100 & $p>0.05$ \\
MYC & 3 & 11.1 & 2 & 66.7 & $p<0.01$ \\
Ki67 $>90 \%$ & & & & & $p<0.05$ \\
\hline
\end{tabular}

Table (3): Cytogenatic and prognostic data of the diagnosed groups after FISH.

\begin{tabular}{|c|c|c|c|c|c|}
\hline \multirow{3}{*}{ Cytogenatic } & \multicolumn{4}{|c|}{ Diagnostic Groups after FISH } & \multirow{3}{*}{$\begin{array}{c}p- \\
\text { value }\end{array}$} \\
\hline & \multicolumn{2}{|c|}{ DLBCL $(n=27)$} & \multicolumn{2}{|c|}{ DHL $(n=3)$} & \\
\hline & No. & $\%$ & No. & $\%$ & \\
\hline MYC & 1 & 3.7 & 3 & 100 & $p<0.01$ \\
\hline BCL-2 & 2 & 7.4 & 3 & 100 & $p<0.01$ \\
\hline BCL-6 & 2 & 7.4 & 0 & 0 & $p>0.05$ \\
\hline \multicolumn{6}{|l|}{ Prognostic markers: } \\
\hline High levels of LDH & 20 & 74.7 & 3 & 100 & $p>0.05$ \\
\hline Stage III/IV & 12 & 44.4 & 2 & 66.7 & $p>0.05$ \\
\hline Bone marrow infiltration & 4 & 14.8 & 2 & 66.7 & $p<0.05$ \\
\hline CNS infiltration & 2 & 7.4 & 0 & 0 & $p>0.05$ \\
\hline Extranodal involvement & 13 & 48.1 & 2 & 66.7 & $p>0.05$ \\
\hline Recurrence & 2 & 7.4 & 0 & 0 & $p>0.05$ \\
\hline Death & 13 & 48.1 & 3 & 100 & $p<0.05$ \\
\hline
\end{tabular}

Table (4): Correlation between IHC and Cytogenatic findings in examined cases.

\begin{tabular}{llll}
\hline & No. & FISH +ve & $p$-value \\
\hline Myc: & & & \\
IHC negative & 24 & $3(4.1 \%)$ & 0.667 \\
IHC positive & 6 & & \\
$B C L-2:$ & & $2(12.5 \%)$ & 0.447 \\
IHC negative & 16 & $3(21.4 \%)$ & \\
IHC positive & 14 & & \\
$B C L-6:$ & & $2(9.5 \%)$ & 0.375 \\
IHC negative & 21 & 0 & \\
IHC positive & 9 & & \\
\hline
\end{tabular}



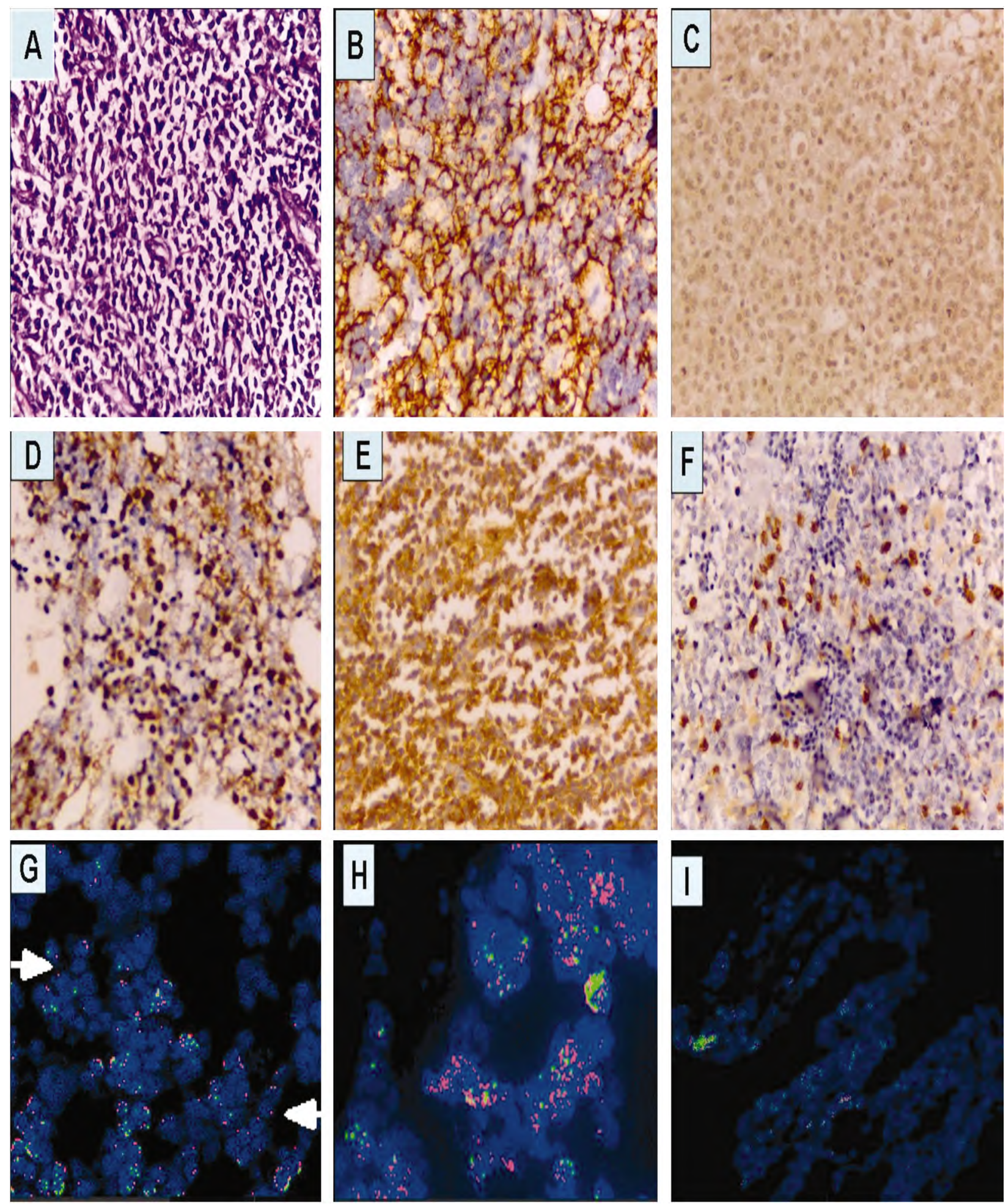

Fig. (1): A case of high grade B-cell lymphoma with MYC, BCL2, rearrangements (double hit lymphoma): H \& Ex 400 (A): With high membranous expression of CD10 (B): Nuclear Ki67 expression (C): Nuclear MYC expression (D): Nuclear BCL2 (E): Nuclear BCL6 (F): (x400), and positive rearrangement of MYC, BCL2, not BCL6 by FISH as separate orange/red and green signals $(\mathrm{G}, \mathrm{H}, \mathrm{I})$. 


\section{Discussion}

Double hit lymphoma is the main element of the B-UNC/DLBCL/BL group. The complementary action of the genes involved, especially MYC that activates proliferation, and BCL2, that antagonize apoptosis in association with other molecular changes could explain the aggressive behaviour of these tumors. It represents about $10 \%$ of B-cell lymphomas and $4 \%$ of high-grade lymphomas $[20,21]$. This first study in Egypt that detected 3 cases of double hit lymphoma out of the 30 cases of DLCL (10\%) with translocations involving MYC and BCL2.

Our results matched to results reported by Landsburg, et al., [22] who found that Double-hit lymphoma is relatively uncommon, occurring in approximately $5 \%$ to $7 \%$ of patients with DLBCL. Dual-expressor lymphomas may be present in as many as one-third of patients with DLBCL.

According to Olivera, et al., [14] the prognosis of DHL is greatly affected by stage at diagnosis, extranodal metastasis, presence of central nervous system or BM infiltration, and if the patient is over 60 years old. The 3 DHL cases in the current study were over 60 years with high LDH; but, two cases out of the three cases presented with advanced stage, BM infiltration, and exhibited extranodal masses.

Our study found a Statistically high significant positive correlation between LDH level, and both of immunohistochemical expression of BCL-2 and death ( $p$-value $p<0.01)$. Similarly, Yadav, et al., [22] reported that lactate dehydrogenase level is high in cases of lymphoproliferative disorders, they affect the outcome can be used to follow the theraputic response and recurrence in cases of NHL.

In the current results, the "necrosis" with "cytoplasmic eosinophilia" in the diffuse large cell lymphoma, the positivity for IHC for Myc in more than 50\% of cells, and positivity for IHC for Bcl2 over than $70 \%$ can be used as potential criteria for selection of cases eligible for FISH. But we recommend additional studies with greater number of cases to analyze such associations; especially study of morphology as it is a suitable and available method of evaluation in routine pathology. Oliveira, et al., [14] recommended the "starry sky" pattern as a suitable selector criteria for eligibility of DLCL cases for cytogenatic study.

Cases of double hit lymphoma have poor outcome.the current results reported that all the cases with double hit lymphoma died, about 4 months after the initial presentation. Li et al., [18], reported that MYC/BCL2 DHL is an aggressive B cell neoplasm and patients often have worse outcome, also, Sonali, et al., [24] concluded that DHL is very proliferative and drug-resistant, and it had worse prognosis. Such aggressive course of DHL may be explained by the synergistic action of MYC and BCL2: Activate proliferation and inhibit apoptosis.

We studied the rate of cell proliferation, through measuring the percent of nuclei stained by Ki67, and studied if it can be used as a criterion for selection the patients eligible for FISH. The cutoff points used was $90 \%$ and a statistically significant difference in the rate of cell proliferation was found between cases of DHL and cases of DLCL $(p<0.05)$. Similarly, Oliveira, et al., [14] found that $12.8 \%$ of patients of DLCL and $66.7 \%$ of DHL patients had high proliferation index (Ki67 >90\%).

The detection of IHC expression of Myc, Bcl2 and $\mathrm{Bcl} 6$ was done in the current study. The cutoff point to determine if MYC and BCL- 6 were positive was $50 \%$, while for $\mathrm{Bcl} 2$, it was $70 \%$. In the current study, a statistically significant positive correlation between IHC and cytogenatic concerning MYC gene and, the BCL2 gene $(p<0.01)$. Correlation between the MYC gene and the BCL2 gene was statistically significant $(p<0.01)$.

Olivera, et al., [25] studied the presence of Myc and $\mathrm{Bcl} 2$ and Bcl- 6 by IHC in Brazalian patients diagnosed as high grade Non-Hodgkin lymphoma, and he correlated these data with their outcome. Patients that were positive, especially if positive for both markers had bad outcome, with increased incidence of mortality. Also Kawamoto, et al., [13] concluded in his study on 61 newly diagnosed cases of DLCL that MYC translocation by cytogenatic study and immunohistochemical overexpression of both MYC (>330\%) and BCL2 (>_30\%) could be independent prognostic factors for overall survival, but MYC overexpression is not a criterion for MYC translocation by cytogenatic study. It is concluded that FISH analysis of MYC translocation and MYC/BCL2 immunohistochemical overexpression are essential predictors for the outcome of DLBCL. Li et al., [18] found that MYC/BCL2 DHL and MYC/BCL6 DHL are aggressive B cell lymphomas and patients often have worse outcome. Similarly, Rosenthal and Younes [5]. Found that cases had DHL showed higher central nervous system metastasis, and prevention is mandatory. Testo, et al., [20] reported that. The MYC/BCL2 DHL patient's had very poor prognosis, and the incidence of mortality was vary high about 18 months after the diagnosis. 
Kasieddy [19]. Found that Double hit gene rearrangements by FISH were detected in $3 / 22$ $(13.6 \%)$ patients. MYC IHC was positive in $8 / 22$ (36.3\%) cases, and 3 of these 8 cases $(37.5 \%)$ were FISH positive. Sensitivity, specificity and concordance of MYC IHC as a screening tool were $100 \%$, $73.6 \%$ and $72.27 \%$, respectively. BCL2 staining was positive in $19 / 22(86.3 \%)$ cases, and only 3 of the 19 cases (15.7\%) were FISH positive. 5/22 (22.7\%) cases showed positivity for both MYC and BCL 2 by IHC (double protein expresser status) and 3 of these $5(60 \%)$ cases showed positivity for DHL status by FISH. DHL biology did not show an association with any clinico-pathological parameters including age, elevated serum Lactate dehydrogenase, extra-nodal disease. Also, Aukema, et al., [10] concluded that MYC (+) lymphomas have to a great extent similar biology with singlehit and DHL, and they share different molecular features.

Kawamoto, et al., [13] emphasize the value of detecting such cases of DLCL, especially as no therapeutic protocol is available. The results of agreement between immunohistochemistry and FISH are very interesting, and can detect the parameters for selection of cases for molecular screening, but it is difficult to standardize criteria of positive cases for Myc and Bcl2 by IHC.

\section{Conclusions}

For our knowledge, this research represents the first research in Egypt concerning series of patients with DHL detected by FISH on 30 cases of highgrade lymphomas. For this research, high grade B-cell lymphomas, especially those showed IHC over-expression of CD10, Ki67, must be submitted to IHC for, at least, Myc andBCL2, BCL6. in cases with overexpression of at least 2 out of the 3IHC markers, Cytogenatic study for MYC, BCL2 and BCL6 must be done as these patients are high grade lymphomas and the molecular markers should be documented.

\section{References}

1- DANIEL J. LANDSBURG: Advancing the management of double hit lymphoma. Oncotarget., Oct., 3; 8 (45): 78245-78246, 2017.

2- HUANG W.1,2, MEDEIROS L.J.1, LIN P.1, et al.: MYC/ BCL2/BCL6 triple hit lymphoma: A study of 40 patients with a comparison to MYC/BCL2 and MYC/BCL6 double hit lymphomas. Mod. Pathol. Sep., 31 (9): 1470-1478, 2018.

3- KHELFA Y., LEBOWICZ Y. and JAMIL M.O.: DoubleHit Large B Cell Lymphoma. Curr. Oncol. Rep. Sep., 26; 19 (11): 74, 2017.

4- KORAC'P., DOTLIC'S., MATULIC'M., et al.: Role of
MYC in B Cell Lymphomagenesis. Genes (Basel). Apr., 8 (4): 115, 2017.

5- ROSENTHAL A. and YOUNES A.: High grade B-cell lymphoma with rearrangements of MYC and BCL2 and/or BCL6: Double hit and triple hit lymphomas and double expressing lymphoma. Blood Rev. Mar., 31 (2): 37-42, 2017.

6- DENNIS P. O'MALLEY, AARON AUERBACH, et al.: Evaluation of Diffuse Large B-Cell Lymphoma and Related Large B-Cell Lymphomas. Arch. Pathol. Lab. Med. Vol. 139, September, 2015.

7- MIYAOKA M., KIKUTI Y.Y., CARRERAS J., et al.: Clinicopathological and genomic analysis of double-hit follicular lymphoma: Comparison with high-grade B-cell lymphoma with MYC and BCL2 and/or BCL6 rearrangements. Mod Pathol. Feb., 31 (2): 313-326, 2018.

8- YE Q., XU-MONETTE Z.Y. and TZANKOV A.: Prognostic impact of concurrent MYC and BCL6 rearrangements and expression in de novo diffuse large B-cell lymphoma. Oncotarget. Jan., 19; 7 (3): 2401-16, 2016.

9- ELDESSOUKI T., HANLEY K., HAMADEH F., et al.: Triple hit" lymphomas: A retrospective cytology case series of an uncommon high grade B-cell malignancy with C-MYC, BCL-2 and BCL-6 rearrangements. Diagnostic Cytopathology, July, 25, 2018.

10- AUKEMA S.M., KREUZ M., KOHLER C.W., et al. Biological characterization of adult MYC-translocationpositive mature B-cell lymphomas other than molecular Burkitt lymphoma. Haematologica. Apr., 99 (4): 726-35, 2014.

11- CHISHOLM K.M., BANGS C.D., BACCHI C.E., et al.: Expression profiles of MYC protein and MYC gene rearrangement in lymphomas. Am. J. Surg. Pathol. Mar., 39 (3): 294-303, 2015.

12- De JONGE A.V., ROOSMA T.J., HOUTENBOS I., et al. Diffuse large B-cell lymphoma with MYC gene rearrangements: Current perspective on treatment of diffuse large B-cell lymphoma with MYC gene rearrangements; case series and review of the literature. Eur. J. Cancer. Mar., 55: 140-6, 2016.

13- KAWAMOTO K., MIYOSHI H., YOSHIDA N., et al.: MYC translocation and/or BCL 2 protein expression are associated with poor prognosis in diffuse large B-cell lymphoma. Cancer Sci. Jun., 107 (6): 853-861, 2016.

14- OLIVEIRA C.C., APARECIDA M., DOMINGUES C. et al.: Double hit and Triple hit Lymphomas: New perspectives for their classification. EMJ Hematol., 5 (1): 95-103, 2017.

15- SAKR H. and COOK J.R.: Identification of "Double Hit" Lymphomas Using Updated WHO Criteria: Insights From Routine MYC Immunohistochemistry in 272 Consecutive Cases of Aggressive B-Cell Lymphomas. Appl. Immunohistochem Mol. Morphol. Apr., 7, 2018.

16- MIAO Y.1, HU S.2, LU X.2, et al.: Double-hit follicular lymphoma with MYC and BCL2 translocations: A study of 7 cases with a review of literature. Hum. Pathol. Dec., 58: 72-77, 2016.

17- WANG W., SHIMIN HU, XINYAN LU, et al.: Triple-hit B-cell Lymphoma With MYC, BCL2, and BCL6 Translocations/Rearrangements: Clinicopathologic Features of 
11 Cases. American Journal of Surgical Pathology, 39 (8): 1132-9, 2015.

18- LI S., DESAI P., LIN P., YIN C.C., et al.: MYC/BCL6 double-hit lymphoma (DHL): A tumour associated with an aggressive clinical course and poor prognosis. Histopathology. Jun., 68 (7): 1090-8, 2016.

19- KASIREDDY V.: Double Hit Lymphomas: Role of Immunohistochemistry in the Era of Florescent in-Situ Hybridization. Blood, 128: 5405, 2016.

20- TESTO N., OLSON L.C., SUBRAMANIYAM S., et al.: Primary Cutaneous Diffuse Large B-Cell Lymphoma With a MYC-IGH Rearrangement and Gain of BCL2: Expanding the Spectrum of MYC/BCL2 Double-Hit Lymphomas. Am. J. Dermatopathol. Oct., 38 (10): 769-74, 2016.

21- NGUYEN L., PAPENHAUSEN P., and SHAO H.: The Role of c-MYC in B-Cell Lymphomas: Diagnostic and Molecular Aspects. Genes (Basel). Apr., 8 (4): 116, 2017.
22- LANDSBURG D.J., PETRICH A.M., ABRAMSON J.S., et al.: Impact of oncogene rearrangement patterns on outcomes in patients with double-hit non-Hodgkin lymphoma. Cancer. Feb., 15; 122 (4): 559-64, 2016.

23- YADAV C., AHMAD A., D'SOUZA B., et al.: Serum Lactate Dehydrogenase in Non-Hodgkin's Lymphoma: A Prognostic Indicator. Indian J. Clin. Biochem. Apr., 31 (2): 240-242, 2016

24- SONALI M. SMITH, M.D.: Aggressive B-Cell Lymphoma: The Double-Hit and Double-Expressor Phenotypes. Clinical Advances in Hematology \& Oncology, January Volume 15, Issue, 2017.

25- OLIVEIRA C.C., MACIEL-GUERRA H., KUCKO L., et al.: Double-hit lymphomas: Clinical, morphological, immunohistochemical and cytogenetic study in a series of Brazilian patients with high-grade non-Hodgkin lymphoma. Diagn. Pathol., 12: 3, 2017.

\section{قيمة تزا من ظهور الدلالات (بى سى الج) و(أم واى سلى) و/أو (بى سلى الج )

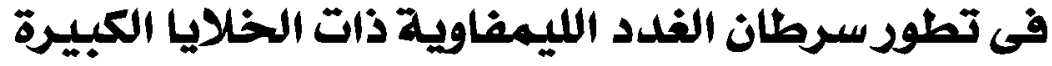

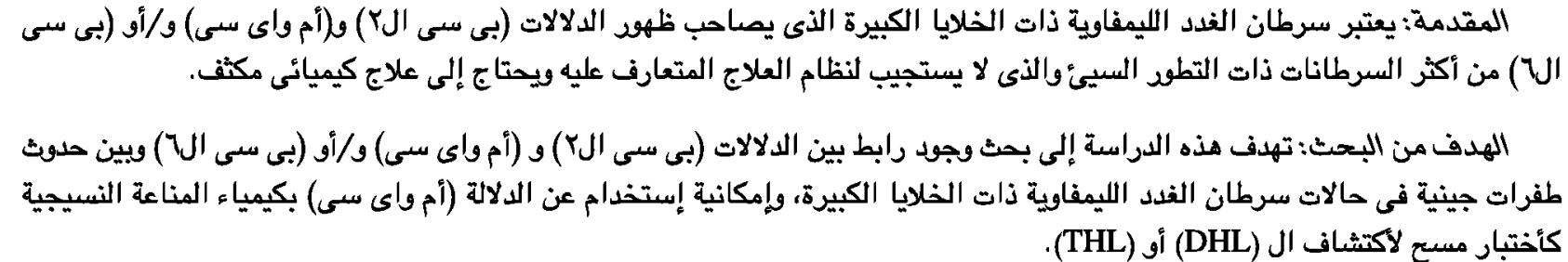

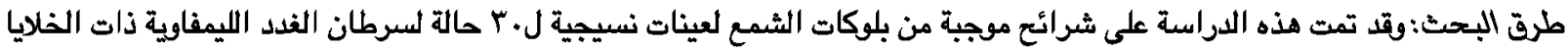

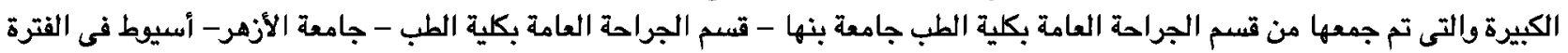

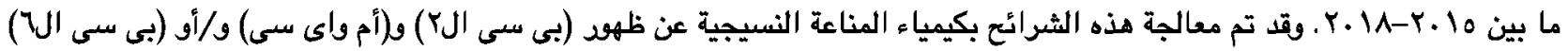
وكذلك تم إجراء إختبار (فيش) للكشف عن هذه الدالالات.

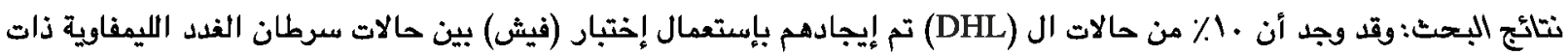

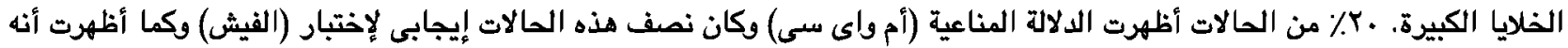

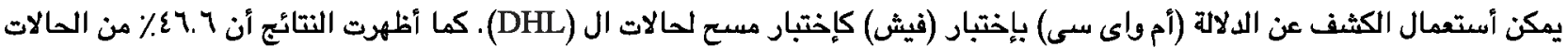

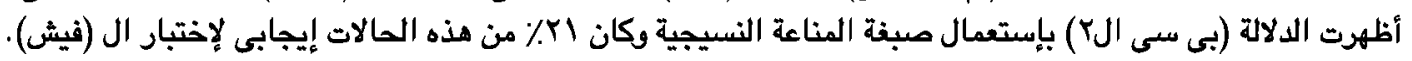

خلاصة البحث: وقد خلصت هذه الدراسة إلى أن ظهود ال (أم واى سى) بإستعمال صبغة المناعة النسيجية وإختبار (فيش). ذات أهمية إحصائية عالية. وكما أظهرت أنه يمكن أستعمال الكثف عن الدلالة (أم واى سى) بإختبار (فيش) كإختبار مسح اللكثف عن حالات ال (DHL). 